\title{
Crime Data Visualization for the Future
}

Andrew P. Wheeler ${ }^{1, * *}$,

**Corresponding author, email: apwheele@gmail.com

1. School of Economic, Political, and Policy Sciences -- Criminology Program

The University of Texas at Dallas

800 West Campbell Road, Mail Station GR 31

Richardson, Texas 75080-3021

Andrew P. Wheeler is an Assistant Professor of criminology at the University of Texas at Dallas in the School of Economic, Political, and Policy Sciences. His research focuses on the spatial analysis of crime at micro places and practical problems faced by crime analysts. His recent work has been published in the Journal of Quantitative Criminology, Crime \& Delinquency, Security Journal, Cartography and Geographic Information Sciences, the International Journal of Police Science and Management, and the Journal of Investigative Psychology and Offender Profiling. 


\section{Introduction}

This paper is written to go with the panel Crime Data and the Future, for the 2017 American Society of Criminology conference. The topic of data visualization is one I embrace as important for a very simple reason - data visualization is necessary to be able to understand complex, quantitative information. Effective communication of quantitative information is not only necessary to make our academic results understandable to a wider audience of laypeople and policy makers, but to even make them understandable to other academics (and ourselves).

Don't worry when you see a table of 50+ regression coefficients and it makes your head spin I'm a pretty quantitative guy and I can't understand them any better than you. As a field we can do better, and I hope to show a few examples of that in this talk.

The title of this talk - Data Visualization for the Future - is probably a misnomer. I do not think we need fancy developments in technology to be able to accomplish what I think is necessary to greatly improve scientific communication of quantitative information. Line graphs, scatterplots, tables, and maps - all easily created in current software - will get us most of the way to where we need to go. While technological improvements like animated and interactive graphics can help in certain circumstances, I personally think that understanding how to reduce data complexity to easier to understand summaries is more important. The only way I know of how to do that is through general quantitative education and via anecdotes. So indulge me for a bit and live through some examples I've been working on or thinking about recently.

\section{Defining Data Visualization}

First before we talk about data visualization it is important to define what data visualization is. Most academics take a Potter Stewart approach (Healy and Moody, 2014), but this I think encourages too small of scope for talking about data visualization. ${ }^{1}$ Here I will define data visualization straight from Edward Tufte: data visualization can be defined as the visual display of quantitative information (Tufte, 2001). While the most common examples that spring to mind are graphs displaying geometric elements where the coordinate system is defined by the data (e.g. bar and line graphs), this ignores things like tables or ISOTYPE like glyphs. ${ }^{2}$

Tables in particular should be considered alongside other data visualizations, as there are clear ways that constructing tables can make them easier to understand based on the same gestalt visual theory. The simplest example is how children learn to add and subtract numbers. So is it easier to calculate $1560000+300000$ (sideways) or the way below?

\footnotetext{
${ }^{1}$ I have a longer critique of Healy and Moody (2014) on my blog, https://andrewpwheeler.wordpress.com/2013/12/02/a-comment-on-data-visualization-in-sociology/.

2 The acronym ISOTYPE stands for the International System of Typographic Picture Education. See many examples discussing ISOTYPE on Robert Kosara’s blog, Eager Eyes, e.g. https://eagereyes.org/techniques/isotype. A great example applying ISOTYPE like glyphs to relevant probability calculations, first suggested by Gerd Gigerenzer (Gigerenzer and Hoffrage, 1995; Gigerenzer, 2015), can be seen on David Spiegelhalter's blog, Understanding Uncertainty, https://understandinguncertainty.org/using-expected-frequencies-when-teaching-probability. While those are not criminal justice examples, they could be easily applied to questions such as "What is the probability that the 10 individuals classified as high risk will actually recidivate?”.
} 
The way below is easier, and it is why children are taught that way. This also displays one central tenet of data visualization - comparing lengths along an aligned axis is much easier than comparing on non-aligned axes (Cleveland and McGill, 1984). Take the image below - which bar is longer, the orange or the blue?

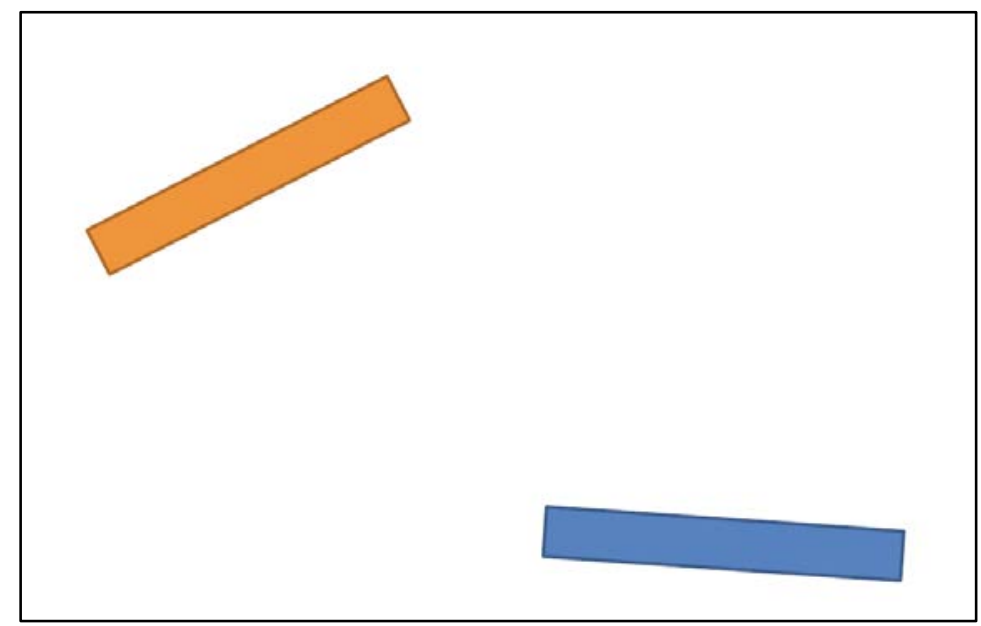

Figure 1: Which bar is longer - orange or blue?

You may get the answer right, but it takes a bit of work. Now consider the same task when the bars are lined up.

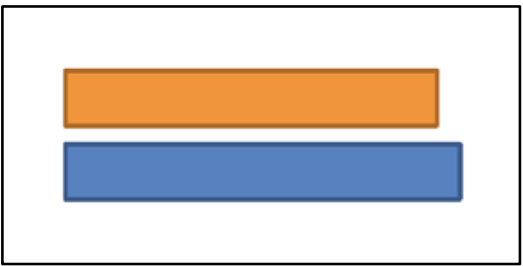

Figure 2: Now which bar is longer?

It is much easier and takes no mental effort - it is immediately obvious.

So now that we have established that it is easier to compare numbers in columns than it is in rows, one simple improvement to the majority of tables in current publications are to arrange the 
table in the orientation you want to make comparisons. For example, most regression tables are laid out like this:

Table 1: Example table showing regression coefficients
\begin{tabular}{rrrr} 
Model 1 & Model 2 & Model 3 \\
Variable & B (SE) & B (SE) & B (SE) \\
\hline A & $2.5(1.0)$ & $1.5(1.0)$ & $0.3(1.0)$ \\
B & $-1.3(2.0)$ & $-0.7(0.8)$ & $-0.3(0.1)$ \\
C & $0.2(0.5)$ & $-0.5(0.4)$ & $0.3(0.6)$ \\
\hline
\end{tabular}

Here we are mostly interested in the changes in the sizes of coefficients across the different model specifications. That is harder to do though when comparing numbers across rows, so we are better off transposing the table.

Table 2: Example with regression coefficients in columns

\begin{tabular}{|c|c|c|c|}
\hline & A & B & C \\
\hline Model & B (SE) & B (SE) & $B(S E)$ \\
\hline 1 & $2.5(1.0)$ & $-1.3(2.0)$ & $0.2(1.0)$ \\
\hline 2 & $1.5(1.0)$ & $-0.7(0.8)$ & $-0.5(0.1)$ \\
\hline 3 & $0.3(1.0)$ & $-0.3(0.1)$ & $0.3(0.6)$ \\
\hline
\end{tabular}

Other simple improvements are right aligning numbers, using a monospaced font, and reducing the number of digits in tables. No special technology needed, and it would make the majority of tables much easier to understand.

I don't want to dwell on tables too long though. ${ }^{3}$ While they are necessary, they are fundamentally limited in comparing complex information. It is easy to find examples of tables that would be much more succinctly represented as graphs. Here is an example from Felson and Poulsen (2003) - a table of the number of robberies per hour of the day in Albany, New York.

Figure 3 is that same table displayed as a graph. The graph is much more economical in terms of both space and information. This goes for most complex tables - large tables of regression coefficients can similarly be replaced by graphs (Kastellec and Leoni, 2007). In general, tables are good for reference to exact numbers, but graphs are better to evaluate trends in many numbers.

\footnotetext{
${ }^{3}$ I have a blog post, Some notes on making effective tables, that gives more elaborate advice and scholarly references. See http://stats.blogoverflow.com/2012/02/some-notes-on-making-effective-tables/.
} 
Table 3: Robberies by Hour in Albany, NY, 2000

\begin{tabular}{|c|c|c|c|}
\hline Hour & of Day & \# Incidents & $\%$ \\
\hline $5: 00$ & $-\quad 5: 59$ & 8 & 1.97 \\
\hline $6: 00$ & $6: 59$ & 8 & 1.97 \\
\hline $7: 00$ & $7: 59$ & 1 & 0.25 \\
\hline $8: 00$ & $8: 59$ & 7 & 1.72 \\
\hline $9: 00$ & $9: 59$ & 9 & 2.22 \\
\hline 10:00 & $-10: 59$ & 11 & 2.71 \\
\hline $11: 00$ & $-11: 59$ & 5 & 1.23 \\
\hline $12: 00$ & $-12: 59$ & 15 & 3.69 \\
\hline 13:00 & $-13: 59$ & 16 & 3.94 \\
\hline $14: 00$ & $-14: 59$ & 16 & 3.94 \\
\hline $15: 00$ & $-15: 59$ & 22 & 5.42 \\
\hline $16: 00$ & $-16: 59$ & 18 & 4.43 \\
\hline $17: 00$ & - 17:59 & 9 & 2.22 \\
\hline 18:00 & $-18: 59$ & 18 & 4.43 \\
\hline 19:00 & - 19:59 & 20 & 4.93 \\
\hline 20:00 & $-20: 59$ & 35 & 8.62 \\
\hline $21: 00$ & $-21: 59$ & 31 & 7.64 \\
\hline $22: 00$ & $-22: 59$ & 14 & 3.45 \\
\hline $23: 00$ & $-23: 59$ & 28 & 6.90 \\
\hline $0: 00$ & - $\quad 0: 59$ & 22 & 5.42 \\
\hline $1: 00$ & $-\quad 1: 59$ & 29 & 7.14 \\
\hline $2: 00$ & $-\quad 2: 59$ & 18 & 4.43 \\
\hline $3: 00$ & $-\quad 3: 59$ & 28 & 6.90 \\
\hline $4: 00$ & $4: 59$ & 18 & 4.43 \\
\hline
\end{tabular}

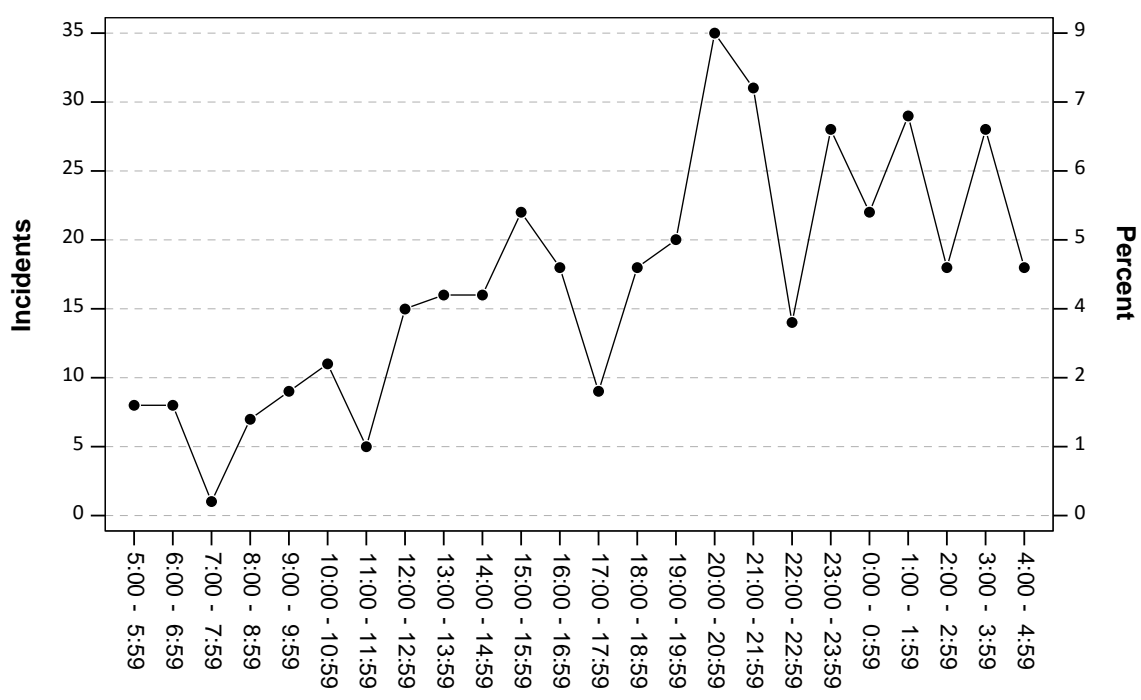

Figure 3: Robberies by Hour in Albany, NY, 2000 


\section{Understanding Complexity}

Data visualization is not and ends in-and-of-itself, but a means to accomplish a particular goal. The basic principles of effective data visualization are very easy to understand in a short period of time. I just presented a major one, comparing along an aligned axis. For those wishing to learn more, I would suggest Albert Cairo's The Functional Art, and for discussion of tables read the academic article by Feinberg and Wainer (2011) as very gentle introductions. ${ }^{4}$

I think my time here though is better spent on showing more examples. Most examples of effective data visualizations will use the same ends (different types of charts you are already familiar with) to display some information summary. Understanding what constitutes an effective summary takes domain knowledge though. There is no way to generalize that - so it is best to see a variety of examples, and hopefully you can relate them to your own particular situation.

\section{Example: Aoristic Analysis of Within Day Burglary Patterns}

The first example I will show illustrates the utility of aoristic analysis (Ratcliffe, 2002). The reason I show this is because it is a quintessential example of summarizing information in a simple, informative way, but one that takes domain knowledge of how criminal justice data is collected to be able to construct.

Using open crime data available for Dallas, TX, Figure 4 displays the distribution of 13,261 burglaries per hour of day in 2015. But those who work with crime data will understand an immediate problem with plotting that information. Burglaries often have an unknown time of occurrence. If you come home from work and find that you have been burglarized, you don't know if it happened at 9 am, or noon, or 2 pm. Figure 4 displays a small multiple graph, using three different summaries of those potential time spans in which the crime takes place - the beginning time, the mid-point, and the end time.

Because if you are reading this you are probably a criminologist, you are probably familiar with the fact that most burglaries occur during the daytime when individuals are at work (Cohen and Felson, 1979). So what is going on with these charts? They each show a substantively different set of patterns.

Instead of reducing what can be very long time periods of unknown occurrences (the median unknown time for burglaries in this dataset is five hours), Ratcliffe (2002) suggested you weight the events. The idea is very simple: if a burglary could have occurred sometime between $1 \mathrm{pm}$ and $3 \mathrm{pm}$ and you aggregate to the hours of the day, that incident would get a weight of 0.5 in the

\footnotetext{
${ }^{4}$ Creating maps is much harder to give a gentle reference that is encompassing of modern visualization research. MacEachren's How Maps Work (2004) is a canonical reference, but is not reasonable for laypeople or undergraduates to consume. A simple start on just general advice would be Jerry Ratcliffe's Top Ten Crime Mapping Tips, http://www.jratcliffe.net/blog/ten-crime-mapping-tips/.
} 
[1:00-2:00) hour bin, and a weight of 0.5 in the other [2:00-3:00) hour bin. Figure 5 is what occurs in the Dallas data if we make that plot. ${ }^{5}$

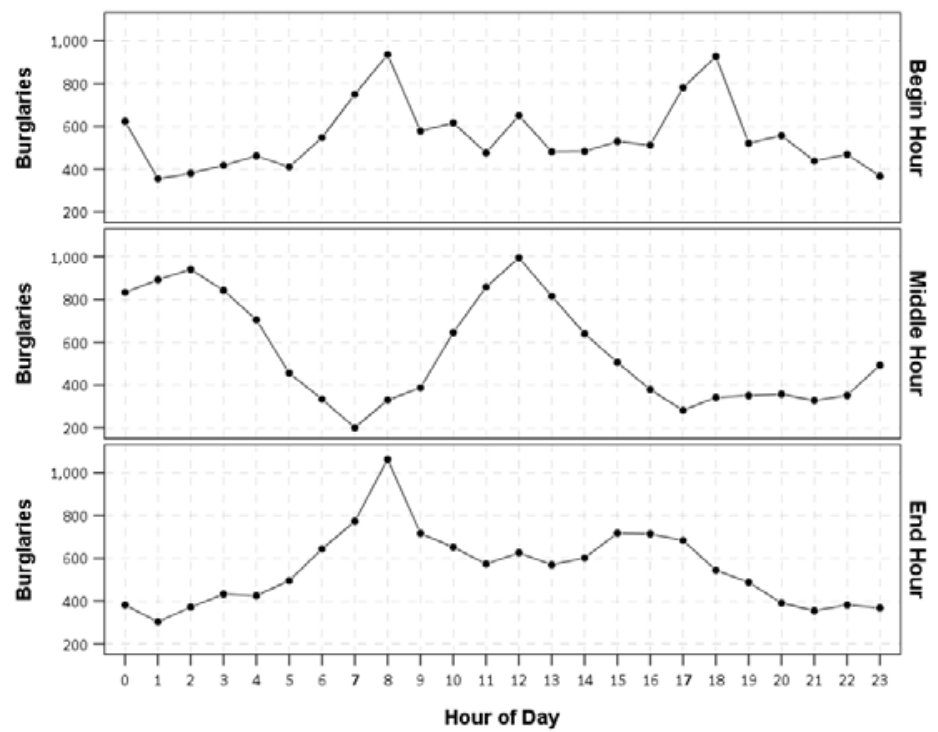

Figure 4: Burglaries by hour of day, represented as either the beginning, middle, or end time the burglary could have occurred.

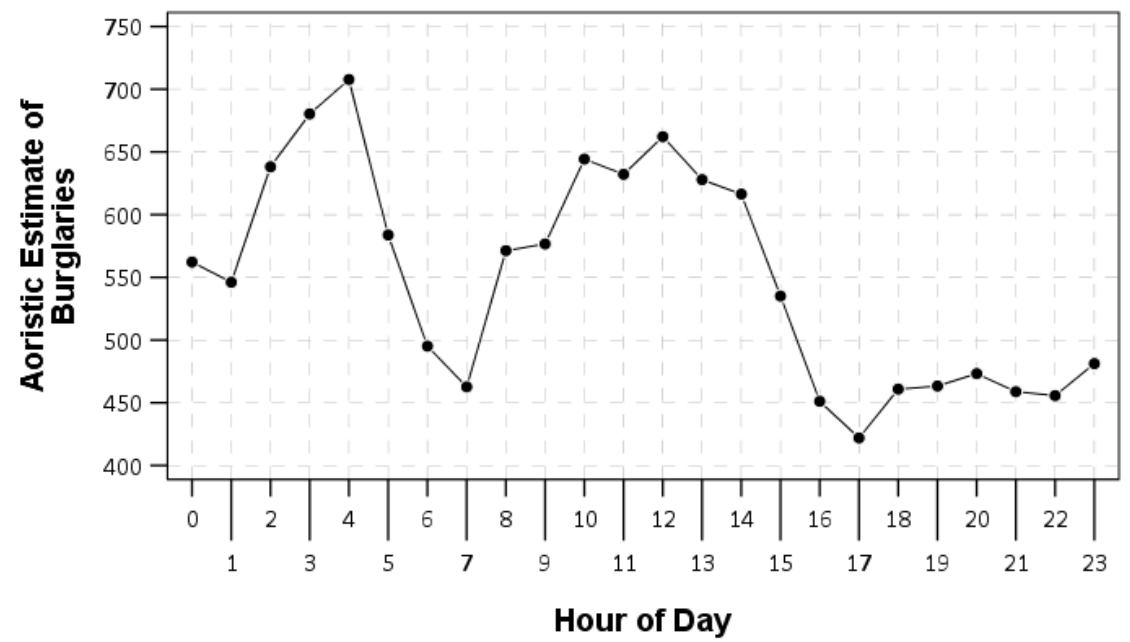

Figure 5: Burglaries by hour of day, estimated via aoristic analysis.

\footnotetext{
${ }^{5}$ Instead of rounding the incidents to the nearest hour, as is done in Ratcliffe (2002), I use continuous weights. So if an incident had a time span of 1:00 to 2:40, it would get a weight of 0.6 in the [1:00-1:59) bin, and a weight of 0.4 in the [2:00-2:59). Boldt and Borg (2016) refer to this as the Aoristic++ algorithm, but others were using this algorithm before they published that paper (see https://andrewpwheeler.wordpress.com/2013/01/30/aoristocratic-analysis-withspss/ for just one example). Additionally for my implementation, if a crime event spans longer than the entire temporal window, all bins are assigned equal weight. So for example, if a crime had an unknown span of 8:00 AM 1/1/2017 through 9:00 AM 1/2/2017 and I aggregated to hours of the day, each hour of the day would get equal weight, 1/24, I do not give more weight to [8:00-9:00) because the event wraps around the full day.
} 
But here we see again an odd spike at nighttime that has a slightly larger peak than the daytime burglaries. Again we need some domain knowledge to be able to explain this pattern. In the Dallas data a large proportion of burglaries are burglaries of commercial establishments, over $42 \%$. So what happens is we disaggregate according to commercial vs. residential burglaries? We get a much clearer picture.

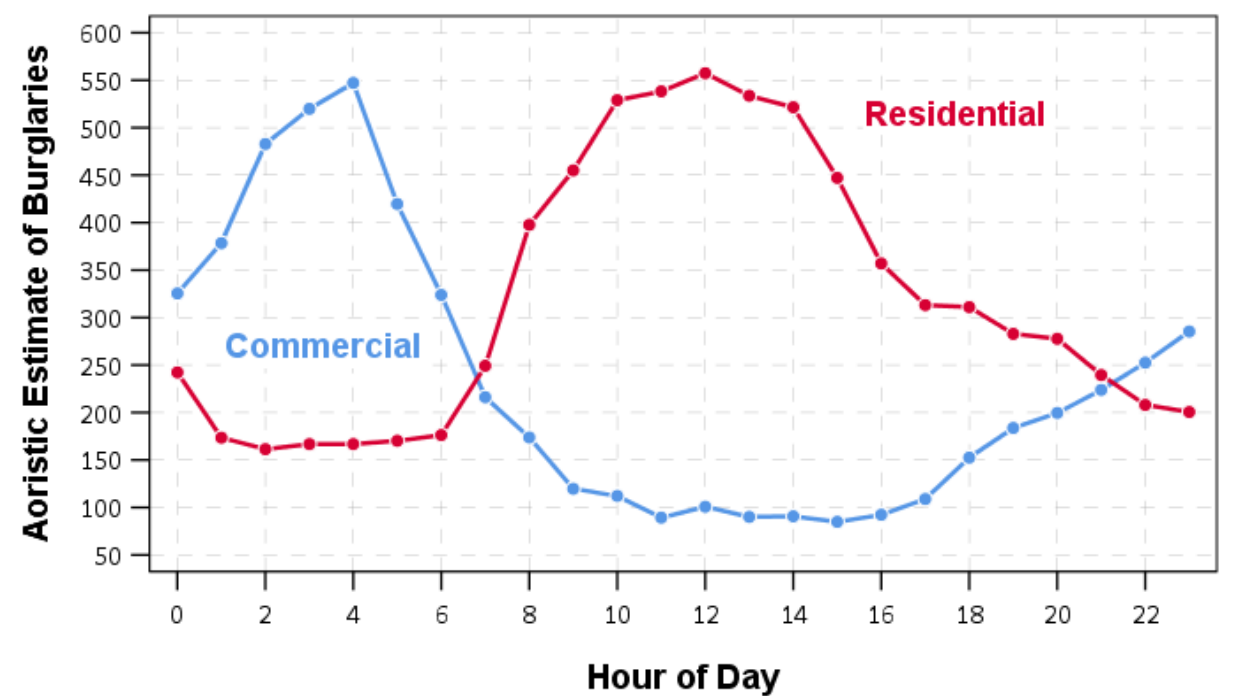

Figure 6: Residential and commercial burglaries by hour of day, estimated via aoristic analysis.

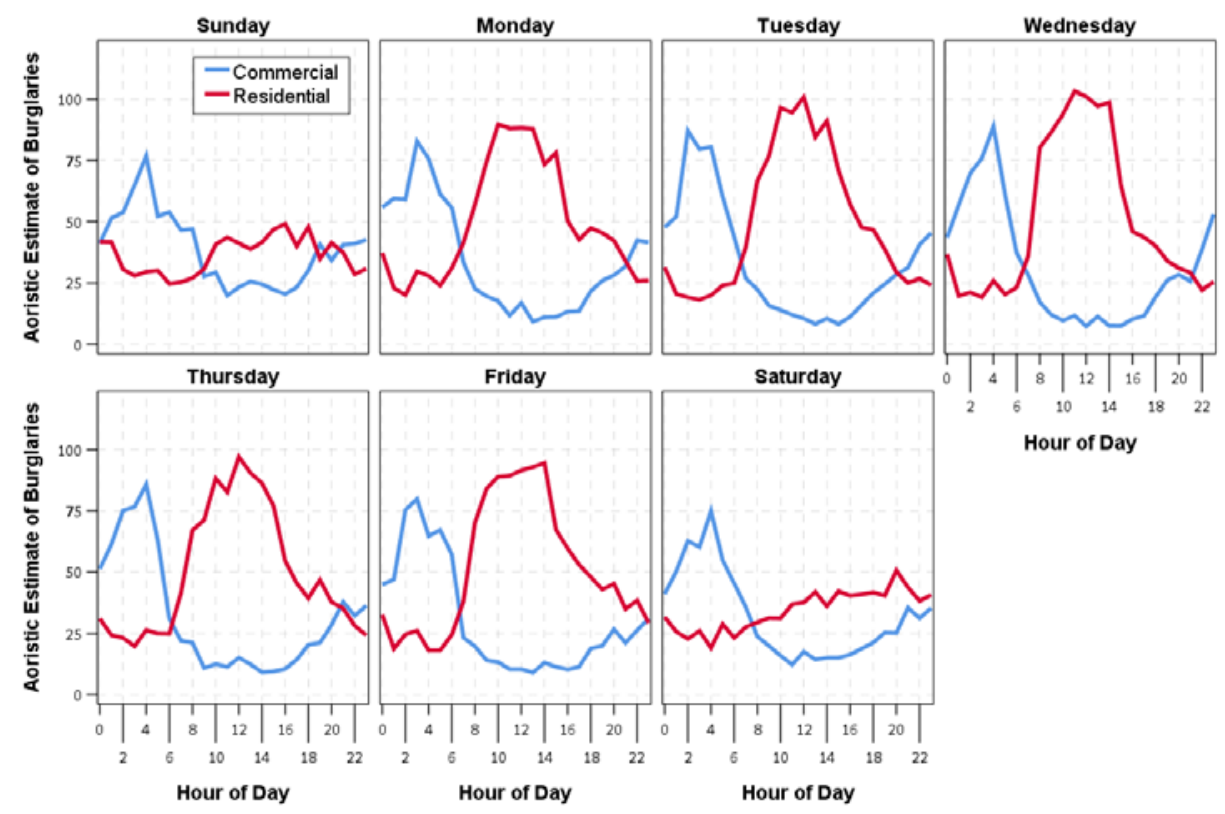

Figure 7: Residential and commercial burglaries by hour of day and day of week, estimated via aoristic analysis. 
It is also interesting to visualize these patterns according to each day of the week (Figure 7). Here you can see that the spike at nighttime is quite regular across each day of the week for commercial burglaries, but residential burglaries show flatter peaks during the weekends. This is what you would expect, as the majority of people work during the weekdays.

Again I highlight this example not because it took fancy graphs to illustrate a clear pattern in the data, but it took specific domain knowledge of crime statistics and some statistical knowledge on how to best aggregate the data. You can make as fancy a chart as you want, you need to know what to chart to begin with to be able to make any sense of any complicated dataset.

Example: Understanding Uncertainty in Homicide Trends

One aspect that frequently came up when I formerly worked as a crime analyst was when to identify if a crime series was rising or falling. In response to that I would typically create many different time series graphs (Wheeler, 2016). Those same lessons I subsequently applied to evaluating whether homicides were increasing or decreasing (Wheeler and Kovandzic, 2017), and I will illustrate a few of those ideas here.

First, lets consider a simple statistical summary - the homicide rate in the United States increased by $18 \%$ from 2014 to 2016 . What does an 18\% increase look like?

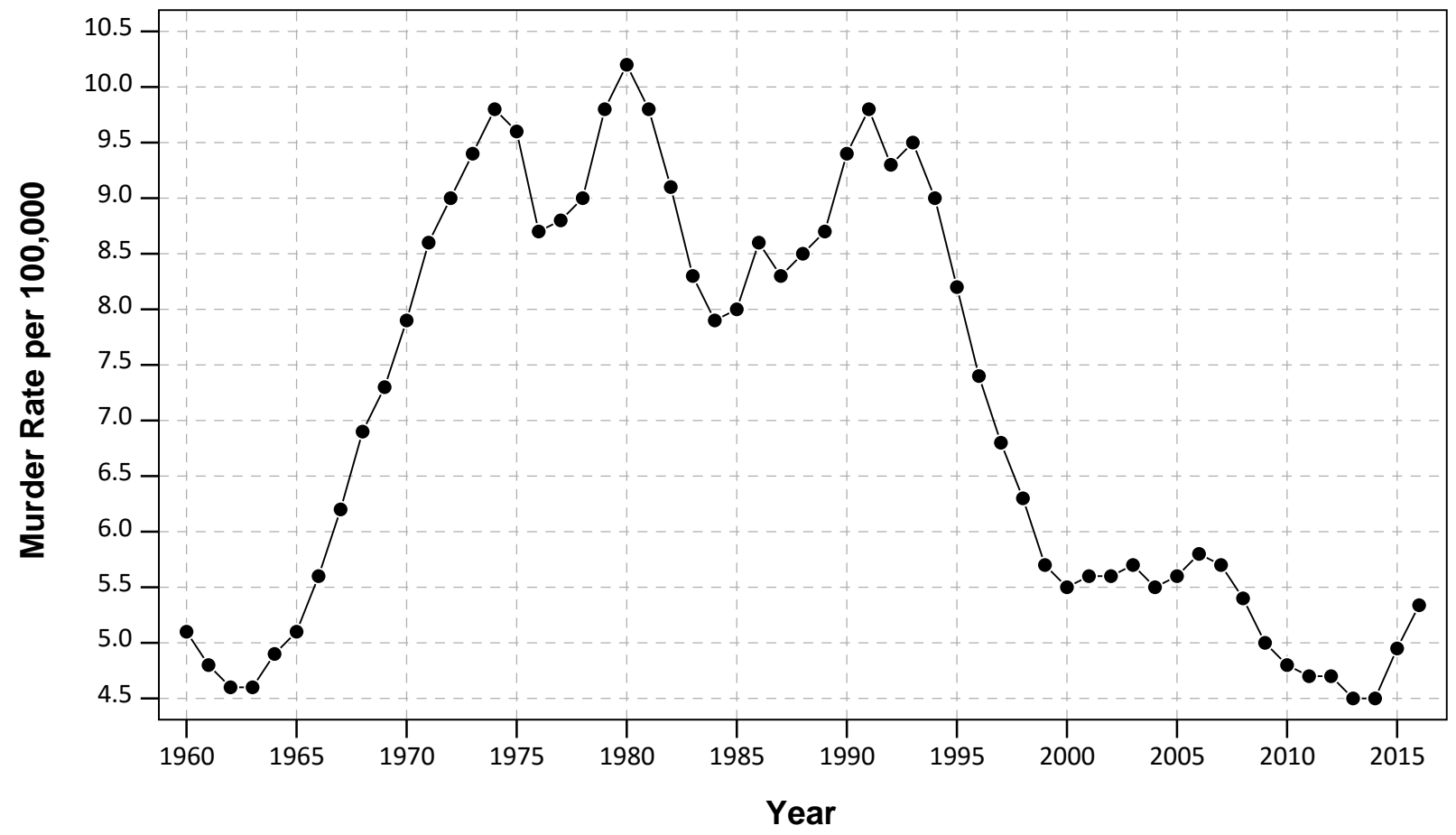

Figure 8: Homicide rates per 100,000 in the United States, 1960 through 2016. 
Of course, simply cherry picking the most recent years makes an $18 \%$ increase seem hyperbole. The percentage change is a particularly volatile statistic prone to making people chase the noise - in pretty much all circumstances you should be interested in examining the long term pattern of any particular crime statistic. To make such a graph is simple, and for homicides the data are readily available to the public. There is no excuse for journalists (or academics) to solely focus on very short term patterns without highlighting historical trends. This is very prevalent in CompStat like meetings for police departments as well. In that they focus on very short term and volatile patterns, especially when using simple summary statistics like percent change.

Now, I will say homicides definitely did increase in the past few years - there is no denying that. But the real question is whether the increase is noteworthy. If you look at enough graphs of data, some will go up and some will go down from year to year. Some call this stochastic variance (Maltz, 1996), but I just call this shit happens. Shit happens that has nothing to do with any particular macro or micro force that could be reasonably hypothesized to relate to crime patterns.

Homicide rates are particularly susceptible to shit happens when examining particular cities, as they are rare enough that random sprees can significantly affect citywide level rates. Take for example my current hometown - Plano, TX. Plano probably gets near the top of the list in nicest/safest large cities in U.S.A. for various rankings, but recently they had a murder of eight individuals in one domestic violence incident (Ballor et al., 2017). This one incident will raise Plano's homicide rate per 100,000 by a little under 3 in 2017, as Plano has a population of a little under 300,000.

Because shit happens all the time, examining graphs that show the crime under evaluation over a long period of time will show the variation due to shit happening from year to year. They will naturally indicate when an increase is abnormal, or when it just appears like the typical year-toyear fluctuation that the series has previously shown. Additionally they will also show long term trends, which are often more pertinent to really understanding why crime is increasing or falling.

When examining city level homicide rates, I also suggested in Wheeler and Kovandzic (2017) a different graph besides the typical time series graph - a funnel chart. Figure 9 displays a funnel chart, with the population size on the X-axis, and the homicide rate per 100,000 on the Y-axis. The grey error bands in the chart denote the expected error around the homicide rate if it were equal to the national average, just under 5 per 100,000 in 2010. In a nutshell, an outlier homicide rate of 15 in a city of over 1 million is a much larger outlier than a homicide rate of 15 in a city with only around 100,000 population.

Estimating these funnel charts going back several decades I noticed a particular pattern - that several cities in the 100,000 to 1,000,000 population range were extremely high outliers, and were outliers going back to the 1970’s and the 1980’s. Cities like Baltimore, Detroit, New Orleans, Kansas City, and Gary were regularly among the highest homicide rate locations. Several of these cities are currently making headlines for recent homicide spikes, but a part of the story that seems to be lost is that these are places that have had really high homicide rates for a long time. Figure 10 displays the trajectories of those cities, compared to three more bellwether cities in terms of the crime decline: Dallas, NYC, and Chicago. 


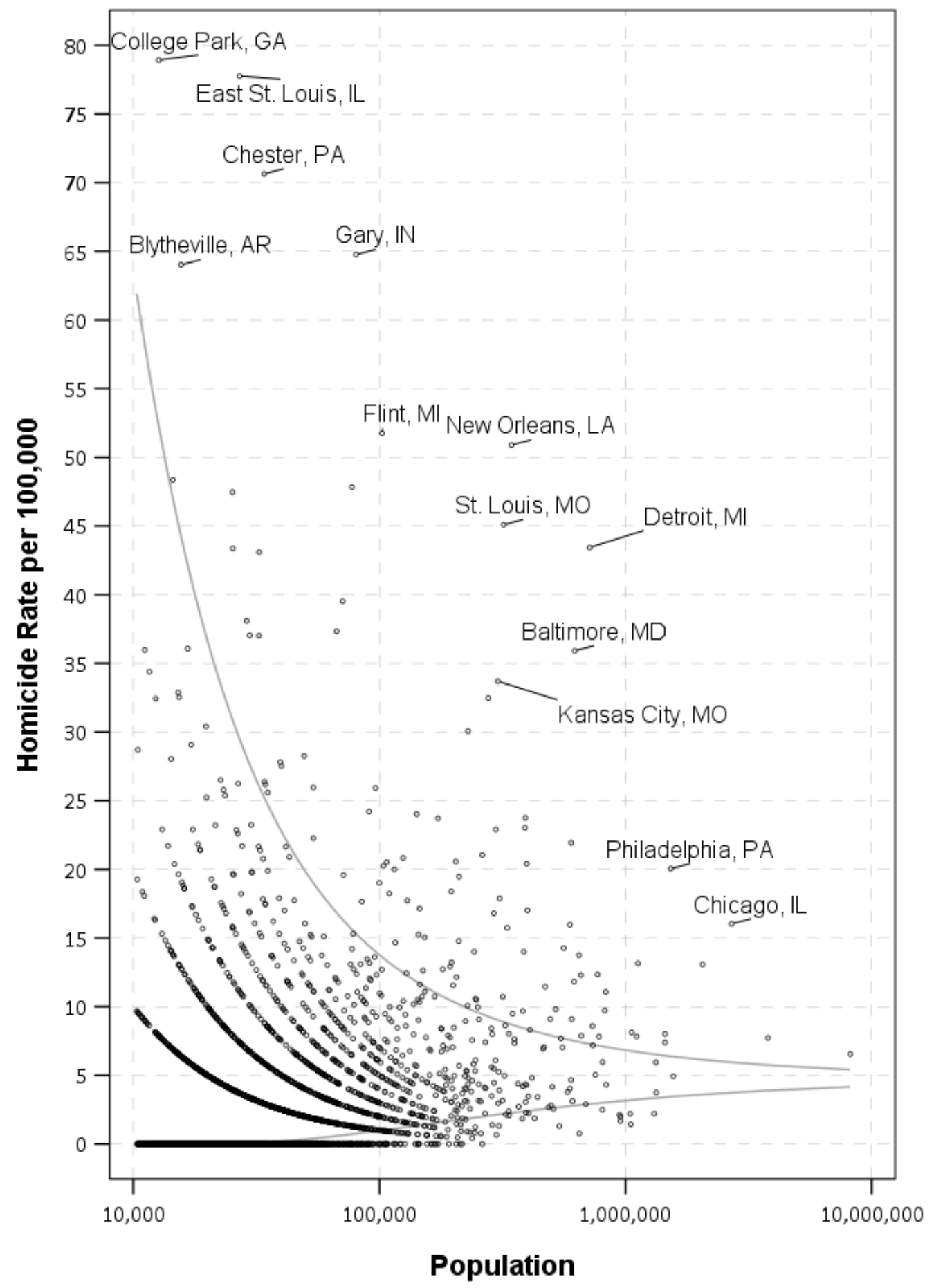

Figure 9: Funnel chart displaying homicide rates in 2010 by population. 

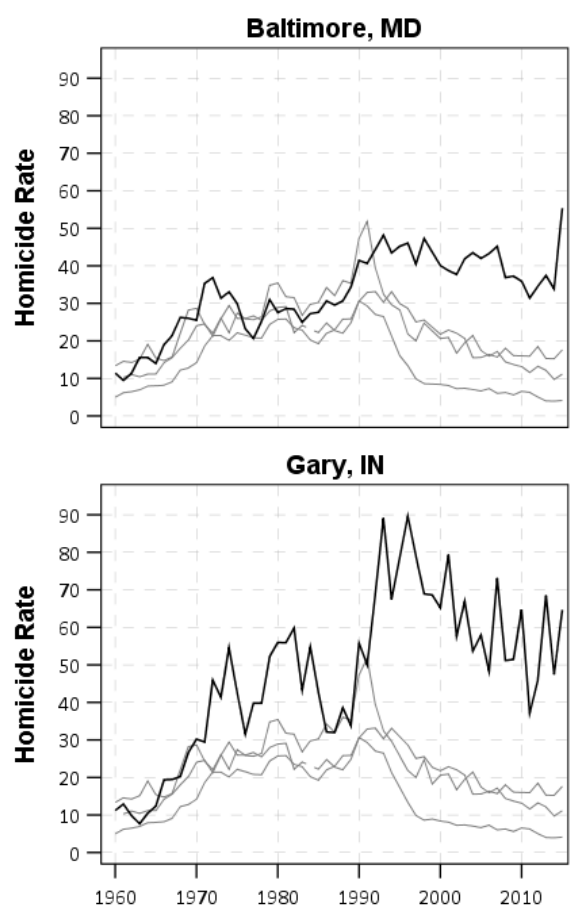

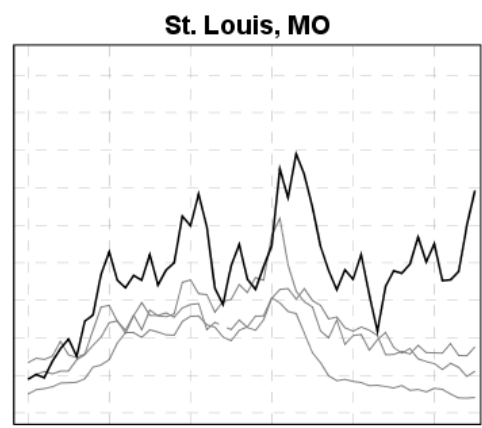

Detroit, MI

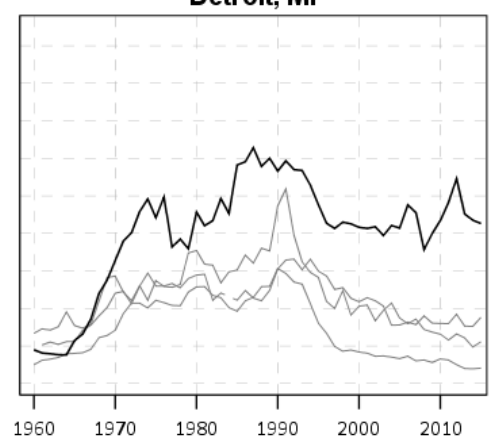

New Orleans, LA

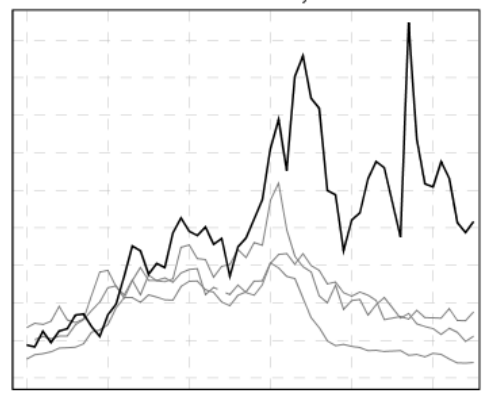

Kansas City, Mo

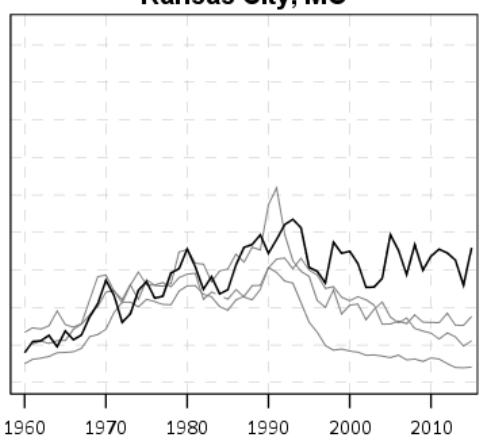

Figure 10: Homicide rates per 100,000 from 1960 through 2015. Grey lines depict the cities of Dallas, New York City, and Chicago, that experienced more typical drops during the great crime decline.

These graphs show the homicide spike in Baltimore in $2015^{6}$, but these cities are really characterized by volatility, and the fact that the great crime decline really did not occur in these cities, at least not like in the majority of the United States. Again, these don't falsify that any recent homicide spike is a significant shift upwards in crime, but they should give us pause to attribute those spikes to purportedly recent factors. It seems to me that explaining these long term historical patterns are more important for policy implications than blaming current spikes on whoever is the most recent scapegoat.

\section{Example: Micro Results have Macro Implications}

Much of my current work has focused on micro spatial analysis - analysis at small geographic units of analysis. Although I am a reductionist, and believe that examining such smaller units provides more information (see Wheeler (2015) for a more detailed account of why I think that is the case), there is a problem with much of the current micro spatial analysis literature (including my own). That problem is that if I say a particular micro level policing intervention reduced a total of 1,000 crimes, that reduction should be visible in the macro level data. Most current policing interventions fail to show any convincing city wide level crime declines - which is what we really care about. Most hot spot policing interventions are much too small to reasonably

\footnotetext{
${ }^{6}$ Baltimore showed increases in additional crimes besides homicides after 2014, see my blog post https://andrewpwheeler.wordpress.com/2017/09/03/graphs-and-interrupted-time-series-analysis-trends-in-majorcrimes-in-baltimore/, based on Pete Moskos’s hypothesis that crime shifted upwards post the riot on 4/27/15.
} 
expect to be able to show appreciable citywide crime declines (see Blattman et al., (2017) for a recent exception). Despite the common assumption that diffusion of benefits is the norm in policing interventions, I suspect crime displacement is still a serious threat, just not in the immediate spatial buffers that are commonly examined, but in a more dispersed array throughout the city. Barr and Pease's (1990) description of displacement as potentially a thin patina I think is the best descriptor of this. The only way to address this is to show macro level crime declines - micro level analysis I do not think will ever be sufficient to show a micro policing strategy is truly effective without displacing crime.

I think a particularly compelling recent example of this is much of the analysis of stop, question, and frisk declines by the NYPD. In short, NYPD saw a dramatic decrease in stops due to civil litigation, but did not see an increase in crime in response. Figure 11 shows the time series trends of the two series. ${ }^{7}$

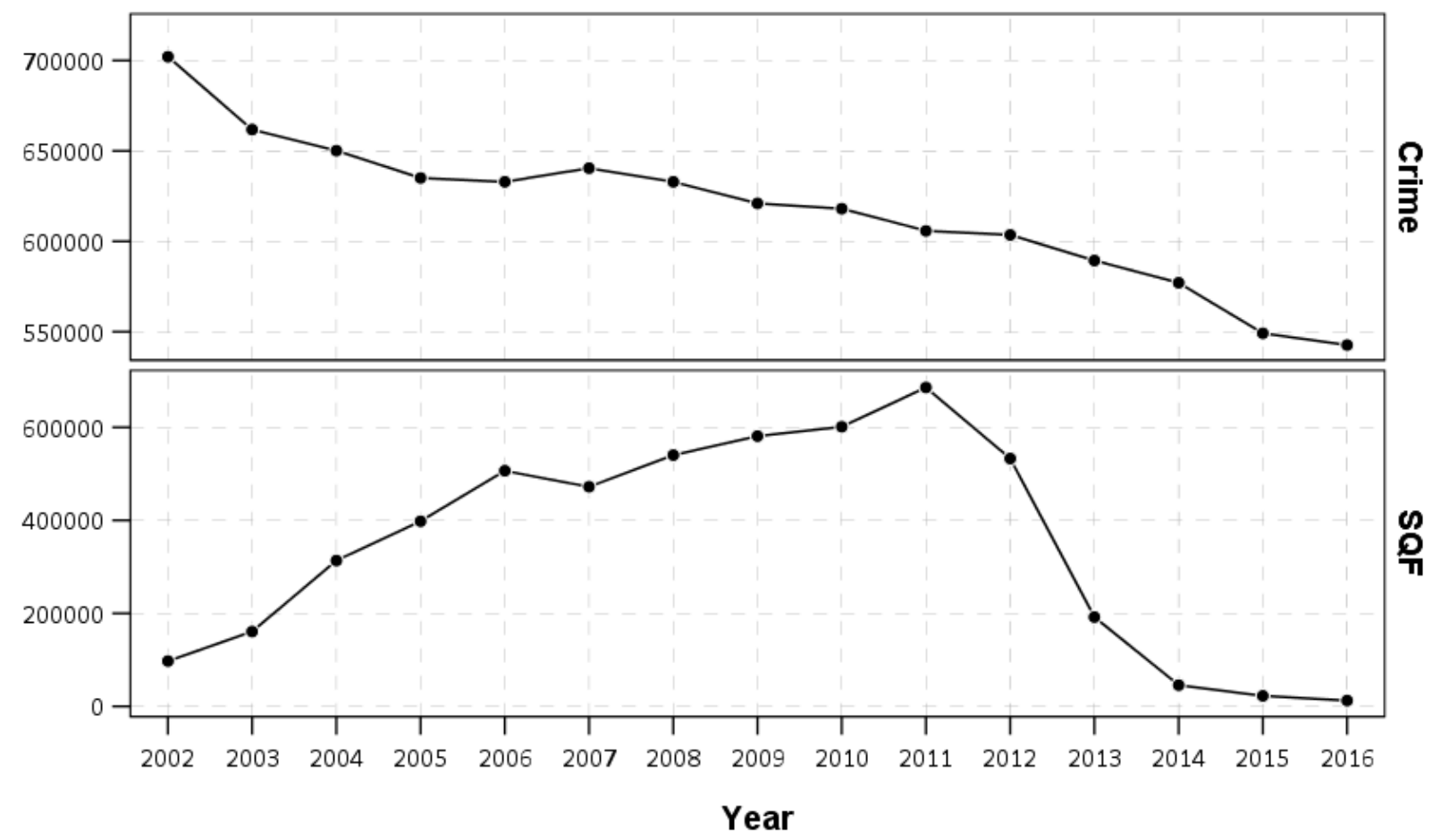

Figure 11: Time series trends of all reported crime in New York City and Stop, Question and Frisks (SQF).

On its face this would seem to be a pretty clear example where the policing intervention could not seriously be considered to decrease crime, but several recent analyses of more micro patterns have suggested that increasing stops decreases crime in New York City (MacDonald et al., 2016; Weisburd et al., 2015). Now, the models are non-linear and include various subsets of crimes and

\footnotetext{
${ }^{7}$ All crime data was calculated from the spreadsheets NYPD provides at http://www1.nyc.gov/site/nypd/stats/crimestatistics/historical.page. The SQF's per year were taken from the NYCLU, https://www.nyclu.org/en/stop-andfrisk-data.
} 
areas, but to get a generally feeling of the impact of results, Weisburd et al. (2016; pg. 41) say that "with a total of 686,000 SQFs in a giver year...we would expect a reduction of 11,771 crimes". Dividing the number of SQF's by crimes gives the estimate that one needs to make 60 stops to reduce 1 crime. MacDonald et al. (2016) makes the argument that particular stops that have higher recorded levels of reasonable suspicion have more deterrent effects, but gives as estimate that 100 stops reduces 3 felony crimes (pg. 9). This subsequently means that you would need 33 stops to reduce one felony crime. Taking these estimates on their face, we can estimate what the macro level trends would look like had there in fact been 500,000 SQF's in 2014, 2015 and 2016. Figure 12 displays those hypothetical outcomes as red lines for both all crimes (top) and only the major felonies (bottom). If you assume there will be more SQF's (say 600,000) it only changes the red lines to be slightly lower, the overall counter-factual trend is still quite similar.

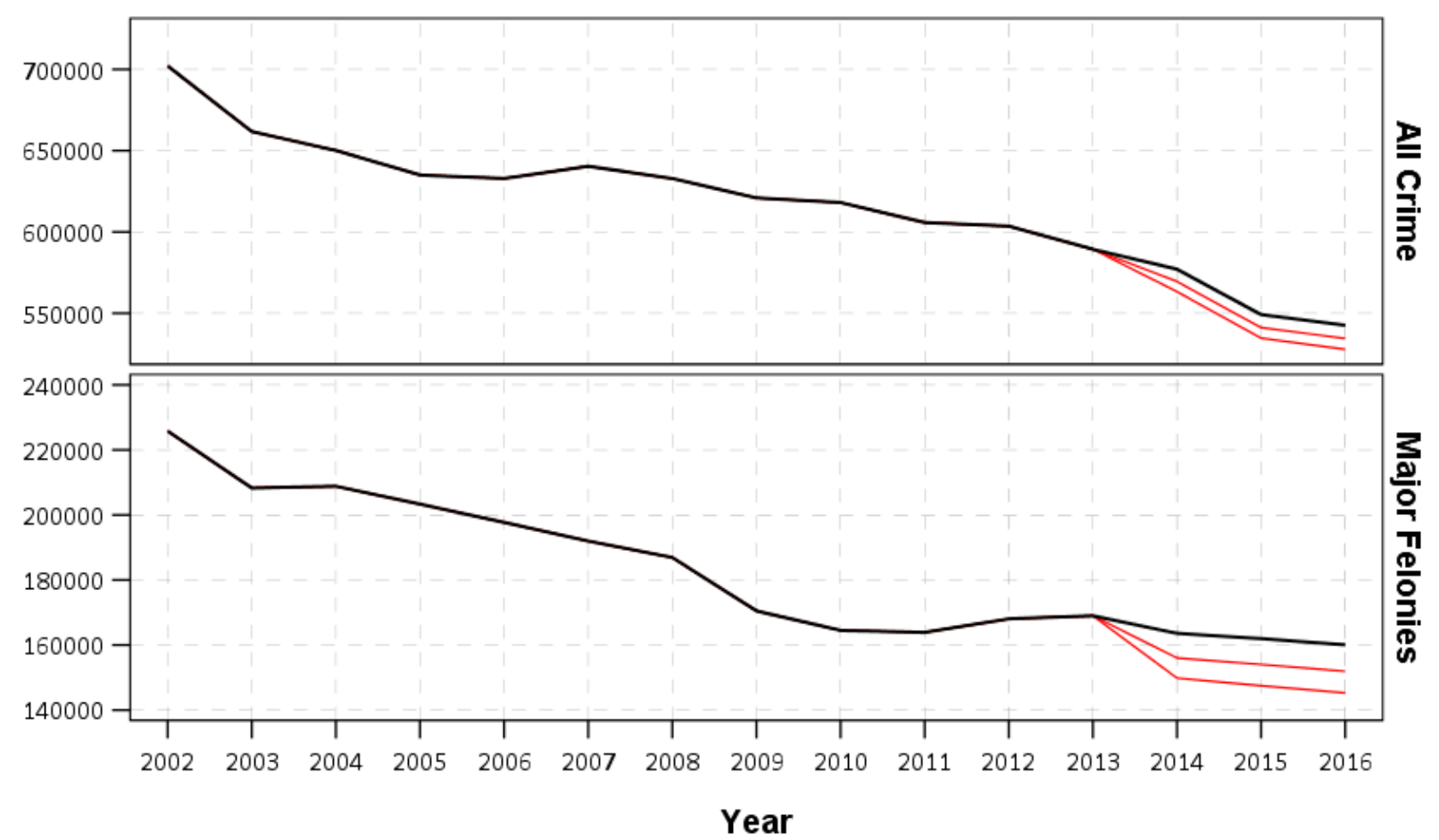

Figure 12: Red lines display the hypothetical number of crimes if 33 or 60 stops results in a reduction of $1 \mathrm{crime}$, and there would be around 500,000 stops in 2014, 2015, and 2016 instead of the observed much lower numbers.

These hypothetical macro level outcomes do not appear implausible on their face, but they also illustrate how hard it might be for particular policing interventions to make a dent in macro level crime trends. A reduction of half a million street stops in New York City only barely moves the needle. 


\section{Example: Complicated Regression and Machine Learning}

The final example I want to talk about is related to predictive algorithms. They are rightly a popular topic in the current news, but in actuality applications of applying predictive (or actuarial) applications towards aspects of criminal justice are really old. Harcourt (2008) provides a historical overview, mostly focusing on parole decisions, but some of the origins of social science in France examined distributions of crime and deviance (e.g. Poisson, Quetelet, Guerry) to try to make predictions of criminality as well.

One of the main benefits of modern machine learning libraries is that they are entirely black box. That is, you can submit a variety of inputs, the machine learns complicated functions from those input variables (aka features) and gives a prediction (Berk and Bleich, 2013). So instead of the researcher having to specify a fully formulated regression equation, e.g.:

$$
\hat{y}=\beta_{0}+\beta_{1}(A)+\beta_{2}(B)+\beta_{3}(C)+\beta_{4}(B \cdot C)
$$

The researcher just needs to know what features to put into the machine, and the algorithm learns whatever complicated functions relate the inputs to the output, and produce a prediction:

$$
\hat{y}=f(A, B, C)
$$

So in the first equation the researcher needs to know that the variables $B$ and $C$ have an interaction, and conditional on that interaction all of the other variables have an additive and linear effect on the outcome, $y$. It is hard to know all that information beforehand: does $A$ have interactions with other variables? Is the relationship between $B$ and $y$ non-linear? Is there a three way interaction between $B, C$, and $A$ ? All you need to know for the machine learning algorithm are what variables to put in - you do not need to specify the structural relationship to the outcome. Even if the relationship in the end is the simple linear and additive one, using the machine learning algorithm is still better, in that it will learn that linear and additive relationship from the data (Berk and Bleich, 2013). ${ }^{8}$

This creates additional problems though, in that it is very hard to know how the inputs relate to the outputs. Do you want to know if $A$ has the strongest relationship to the outcome? Do you want to know if the effect of $B$ is smaller or larger when the value of $C$ is low? The black box nature of the algorithm prevents you from answering those types of causal questions. ${ }^{9}$

Understanding how the inputs relate to the outputs is not only necessary to answer causal questions, but to also understand how the model can be biased and can potentially create disparity among particular groups that deal with these algorithms. In particular, many applications of predictive algorithms in criminal justice applications I believe can potentially result in what I will call the losers keep on losing. In that the systems initially identify particular

\footnotetext{
${ }^{8}$ For some algorithms this is not always true. Tree based algorithms can perform poorly when extrapolating beyond the domain of the observed data, see a simple blog post by Peter Ellis illustrating this, http://ellisp.github.io/blog/2016/12/10/extrapolation.

${ }^{9}$ One can attempt to identify whether factors are strong or interact through variable importance scores, see Wang et al. (2016) for one example. But those statistics do not give a simple interpretation such as increasing $\mathrm{X}$ by a certain amount causes $\mathrm{Y}$ to increase by a certain amount.
} 
groups as high risk (or another marker for a negative outcome), those groups are subjected to further scrutiny by criminal justice agents, and that further scrutiny results in the models continually identifying those groups as high risk.

To illustrate this, I will use an example machine learning algorithm used by the city of Chicago to predict when a restaurant will fail a food inspection. See https://chicago.github.io/foodinspections-evaluation/ for a description of the project, as well as access to the original data sources and all the code used to estimate the regression models. While this is not an example within the criminal justice domain, I hope the applicability of the same type of model to say scheduling probation checks is readily apparent.

The model I will be evaluating is a random forest model (although they additionally have a regularized logistic regression model in the code as well). The features that the city uses to predict which restaurants will fail their inspection are ${ }^{10}$ :

Prob(Fail Inspection $)=f($ sanitation cluster, past failures, time since last inspection, burglaries nearby, sanitation complaints nearby, garbage requests nearby)

When I first saw this, one particular variable I was concerned about was the time since last inspection. In particular I could see how this would result in my losers keep on losing concern. It could be the case that a particular location could have had a recent failed inspection, so the model would predict inspectors should go back to that location shortly after for an additional inspection. This on its face makes sense, but what can happen is a feedback loop. A location that is flagged as a higher probability of failure is given more attention, inspectors record more failures, and that area continues to be high risk (and subsequently continues to have more inspections). The obverse happens for a location initially flagged as low risk. It receives less attention, and is subsequently rated as a lower and lower risk over time due to less scrutiny.

The additional variable sanitation cluster ends up being mostly a geographic clustering of different areas in the city, although the documentation suggests there are different raters assigned to different areas as well. ${ }^{11}$ Figure 13 is a map displaying the different geographic clusters of those areas. While the clusters overlap, some show particularly obvious geographic patterns.

So how do we take the black box random forest model and show how it treats the time since last inspection? The approach I will suggest is not perfect, but I prefer to not let the perfect be the enemy of the good. My suggestion is simple, the model will give you a set of predictions if you give it different inputs, simply change the inputs over ad-hoc values you want to assess, and plot those in various graphs. So for example here, after we fit our random forest model we can

\footnotetext{
${ }^{10}$ They also have variables for how old the restaurant is at the time of inspection (dichotomized into a 0-1 variable), whether they have an on-premise alcohol license, whether they sell tobacco, and what the daily high temperature on the day of inspection.

${ }^{11}$ I have an online map displaying the locations of those areas at https://goo.gl/51iADZ.
} 
generate a set of predictions given different inputs - we then just choose our inputs over a set of values that we are interested in, while holding other covariates constant.

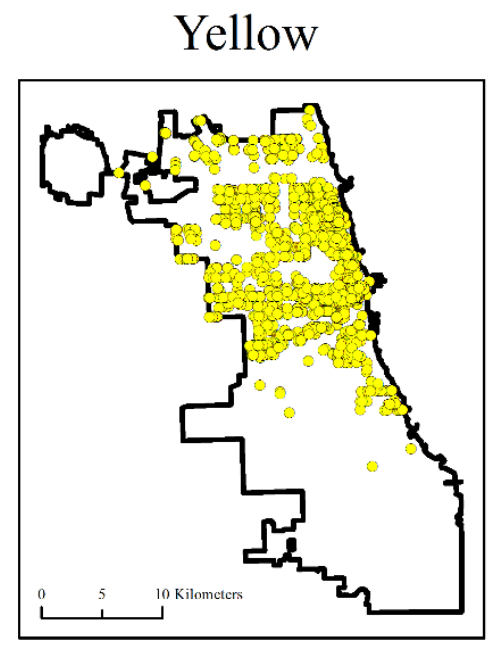

Green

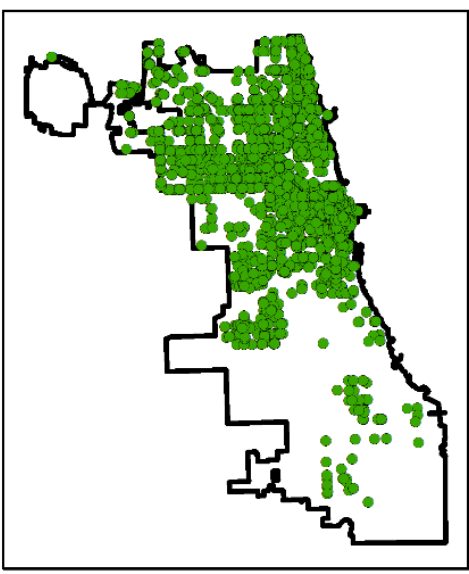

Blue

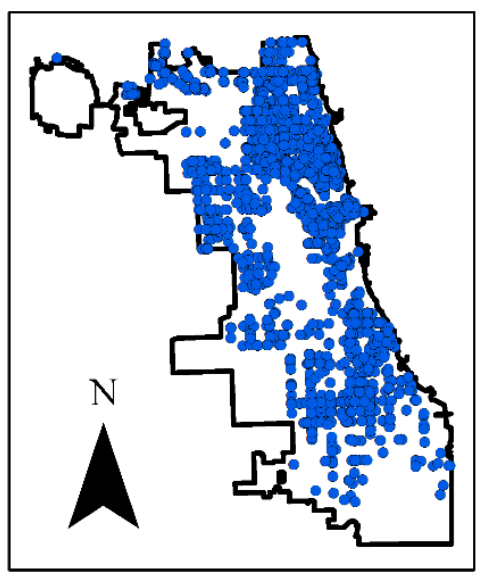

Purple

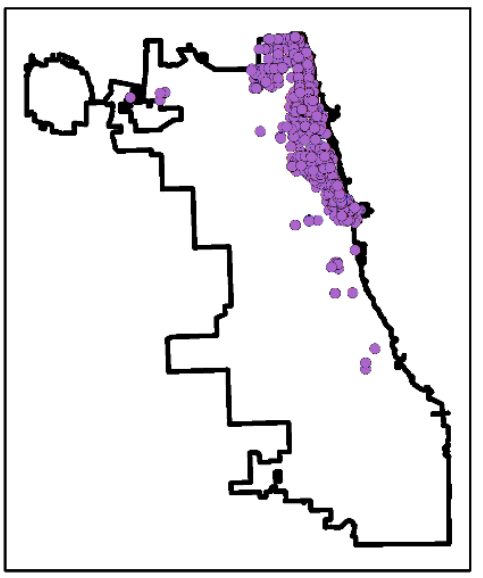

Brown

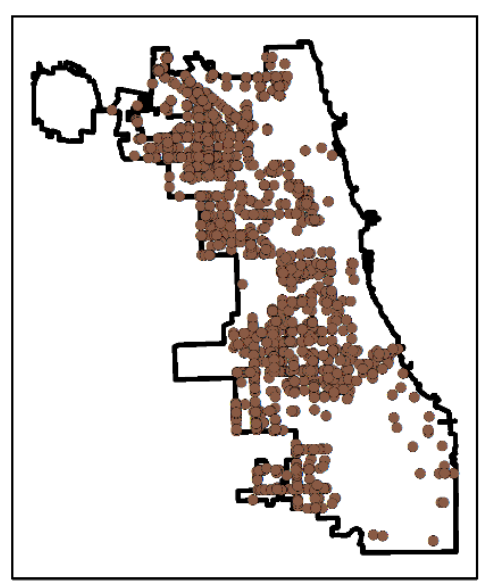

Orange

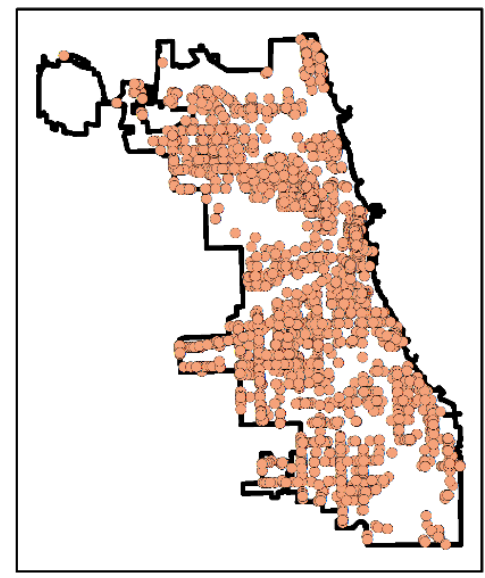

Figure 13: Different sanitation clusters in the city of Chicago. Each cluster has different raters.

In Figure 14 I generate those predictions varying days since last inspection for every 10 days from zero days through two years. I then generate predictions for each area/rater (denoted as different colors). I also vary the prior levels of past failures, which can take on four different categories (failed past serious and/or failed past critical). I then set the other continuous covariates to their means, or the categorical covariates to their model categories. ${ }^{12}$

\footnotetext{
${ }^{12}$ If you would like the code I used to generate any charts or analysis in this paper feel free to send me an email and
} I can forward the code. 

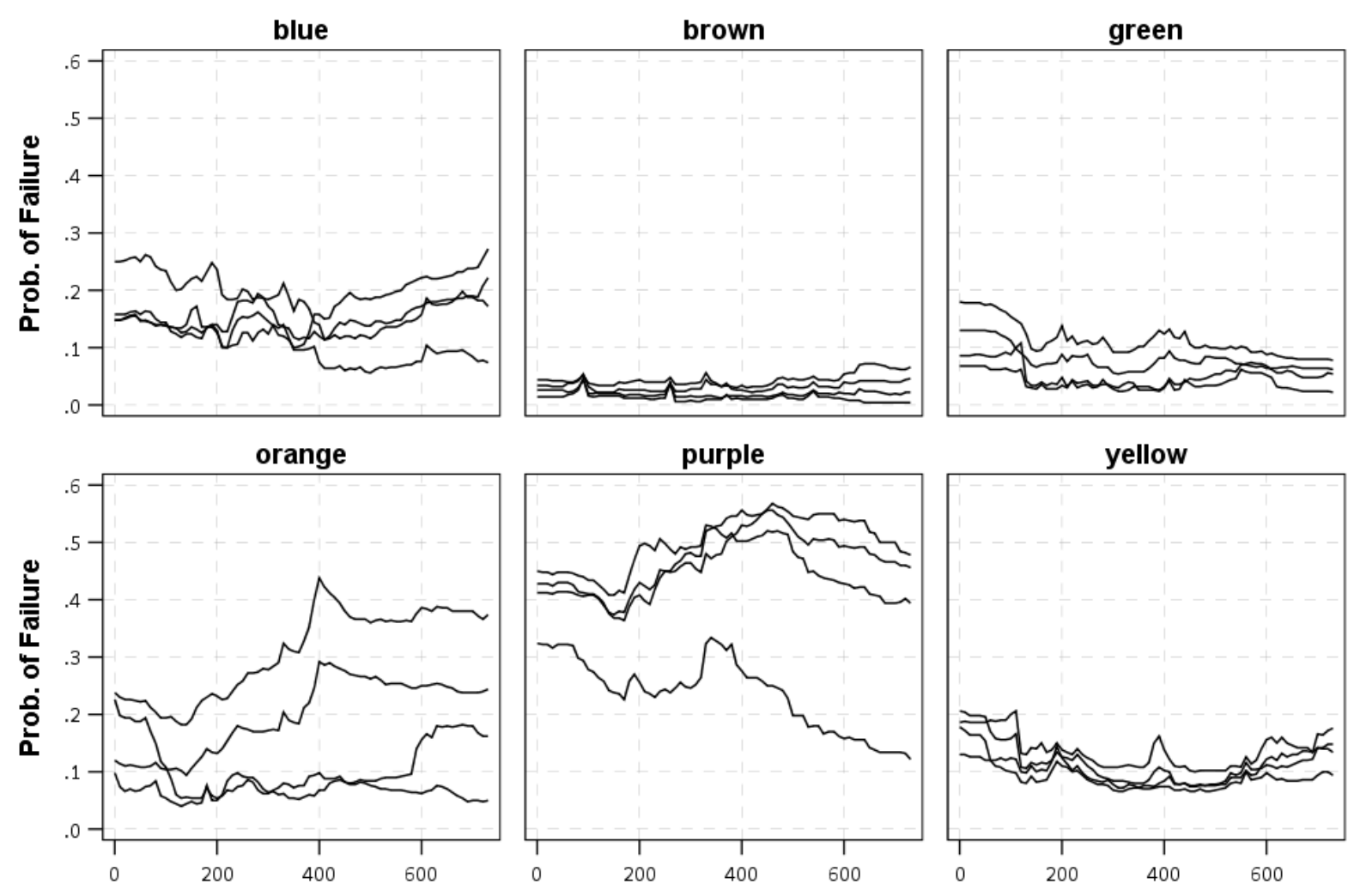

Days Since Last Inspection

Days Since Last Inspection

Days Since Last Inspection

Figure 14: Predicted probability of failing inspection, varying location/inspector and days since last inspection. Lines signify varying levels of prior failures. Other covariates are set to their means (or modal category for categorical variables).

In Figure 14 we can see that the random forest model tends to show decreases from the initial date of inspection, but then have a kink and rise after a period of time. For most areas the period appears to be around one year, but for the orange areas it is sooner. If I had to wager a guess, I suspect the kink is likely due to behavior of past inspectors having around yearly follow ups - I doubt it really signifies failure is more/less likely continuous over time.

Probably the more interesting variation is between areas/raters. The overall average failure in the sample is $14 \%$. Restaurants in the purple area (mostly concentrated in the loop and going up Lake Shore), even if they never previously failed an inspection, by this model will be highlighted as a high probability of failure.

So Figure 14 works out really well for one continuous variable, and then many categorical covariates. Each category will subsequently get a new line. But what about if you want to evaluate interactions between two continuous variables? One way is to create lines just as in Figure 14, but vary the additional continuous variable along regular intervals. Another is to create a heatmap. Figure 15 shows an example heatmap, and Figure 16 shows an example line 
plot. ${ }^{13}$ In this figures, the covariates of past failures were set to zero - this is to signify restaurants that are purely victims of the greater circumstances in which they are situated. They have no personal history that would warrant a high rated risk of failing an inspection.

In this case, in Figure 14 since there are such large variations across areas, each panel is dominated by a particular color. While there are many intricate patterns implied by the model, the graph is not effective in this circumstance of identifying how the inputs are related to the outputs. Figure 15, again using line graphs, I believe does a better job of showing the patterns. Across each panel you can see an interesting pattern that areas of very low burglaries results in higher predictions. In the brown area you are better off having a few burglaries nearby apparently.
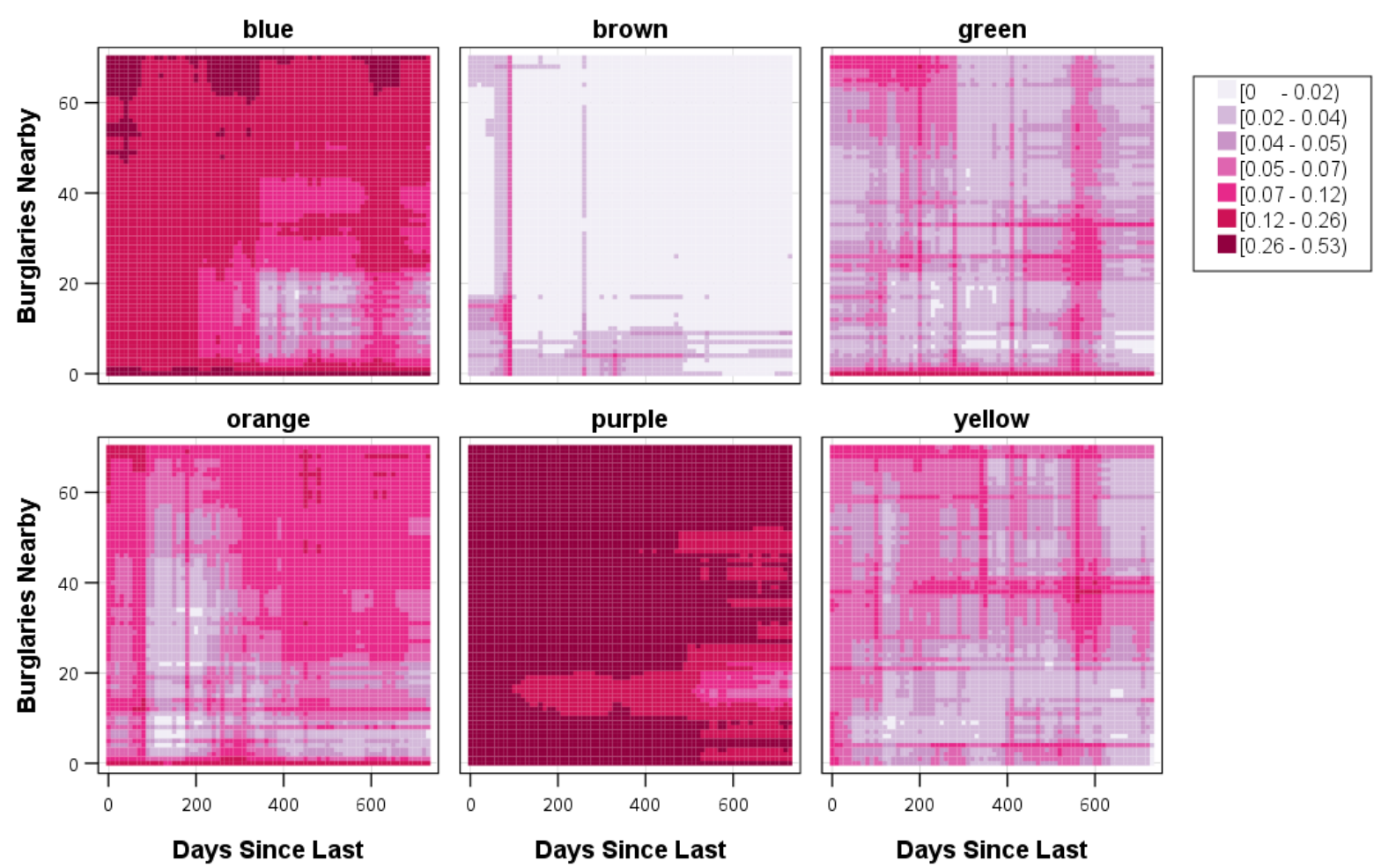

Figure 15: Predicted probabilities across two continuous covariates, burglaries nearby and days since last inspection.

\footnotetext{
${ }^{13}$ Colors for these graphs are taken from http://colorbrewer2.org.
} 

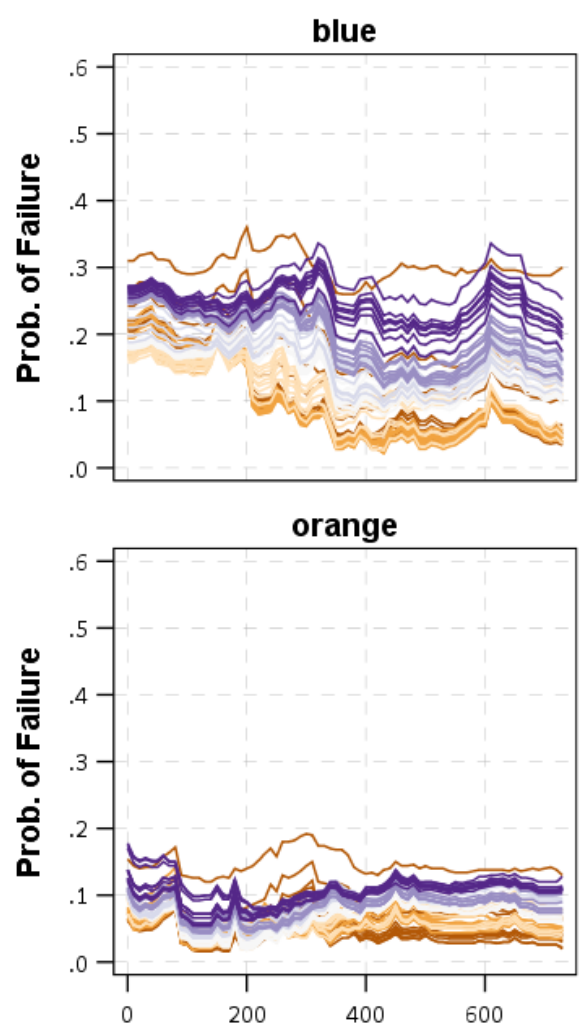

Days Since Last Inspection
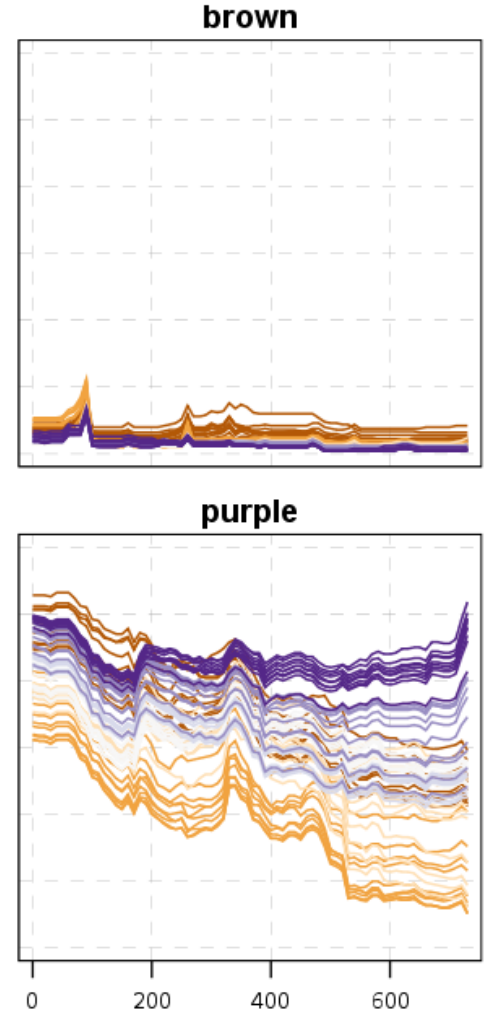

Days Since Last Inspection green

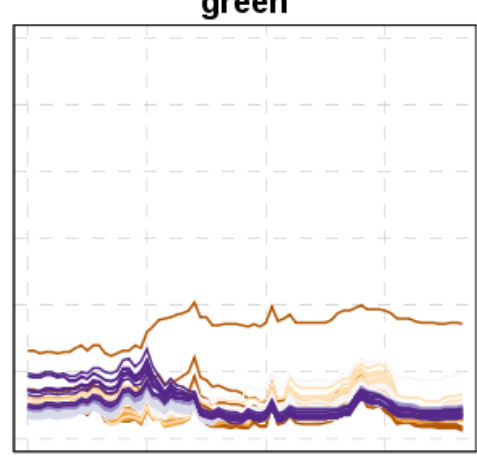

yellow

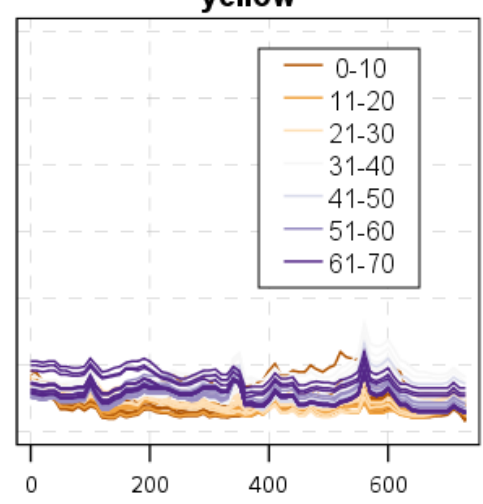

Days Since Last Inspection

Figure 16: Predicted probabilities across two continuous covariates, burglaries nearby and days since last inspection. Line colors signify what the burglaries nearby covariate was set at.

As researchers it is important to be aware of such potential negative externalities from using these machine learning methods to make black box predictions. Part of that is being aware of the particular biases the systems can result in. Here it appears the spatial predictions of different areas/raters should be critically examined.

I would be remiss to not mention additional pieces of work in this area to either make machine learning models fair for particular subgroups (Hardt et al., 2016), or to reduce the complexity of machine learning models to make them more transparent and easier to implement (Goel et al. 2016; Zeng et al., 2017).

Even without using those newer methods though, we can make our models more transparent. The same advice even extends to more typical generalized linear models, which themselves can become very difficult to understand. Just make a set of predictions given the models inputs should be informative about how to interpret the model and understand the magnitude of how much the inputs affect the output in many different situations. It is not perfect, as it relies on specifying an arbitrary set of inputs, but it is better than the alternative of leaving the model a complete black box. 


\section{Discussion}

The takeaway from this talk I want to emphasize is that new visualization methods are not necessary. What we need is deep understanding of the information we are analyzing along with being cognizant of how to effectively present that information in informative summaries.

Unlike many textbook applications of data visualization, data in our field rarely has a nice, clear cut visual relationship. Our models and variables are themselves defined by being very noisy (e.g. it is hard to predict who will commit crime, when they will commit it, or where crime will be committed). Many of the variables of interest to most research applications are also defined by having deep seated interrelationships. Race in particular is difficult (if not impossible) to entirely disentangle from other factors such as space, inequality, and poverty. Reducing complexity while still being informative and fair in criminal justice applications will forever be something researchers in our field will have to grapple with.

Larger datasets and more complicated quantitative analysis are not new to the field, but I suspect it is a safe bet that these aspects will continue to grow in our field in the future. Things like open data make criminal justice information more readily accessible to a wider array of people - but such administrative datasets are not new, and have been regularly analyzed by criminal justice researchers for many years now. It is unlikely that simply by being open are the datasets transparent - we need to train a generation of scholars to have the necessary quantitative skills to make sense of that data, as laypeople are not going to have the prerequisite knowledge to examine a spreadsheet of a million records and be able to produce any new knowledge.

One actual new set of data is the use of sensor data. Such as GPS tracks from cop cars or video feeds from CCTV or body worn cameras (Wain and Ariel, 2013). Reducing the complexity from that information will be an important challenge for future criminal justice researchers. That will not take new data visualization techniques per se, but will likely involve novel ways to take really complicated information and reduce it to ways we can effectively understand it. 


\section{References}

Ballor, Claire, Nanette Light, Jennifer Emily, and Tasha Tsiaperas. (2017). Murder of 8 in Plano shows family violence extends beyond an abusive relationship. The Dallas News, obtained from https://www.dallasnews.com/news/domestic-violence/2017/09/16/murder8-plano-shows-family-violence-extends-beyond-abusive-relationship on 10/30/2017.

Barr, Robert, and Ken Pease. (1990). Crime placement, displacement, and deflection. Crime and Justice 12: 277-318.

Berk, Richard A., and Justin Bleich. (2013). Statistical procedures for forecasting criminal behavior. Criminology \& Public Policy 12(3): 513-544.

Blattman, Christopher, Donald Green, Daniel Ortega, and Santiago Tobón (2017). Pushing crime around the corner? Estimation experimental impacts of large-scale security interventions. SSRN working paper, https://papers.ssrn.com/sol3/papers.cfm?abstract_id=3050823.

Boldt, Martin and Anton Borg. (2016). Evaluating temporal analysis methods using residential burglary data. ISPRS International Journal of Geo-Information 5(9): 148.

Cairo, Albert. (2013). The functional art: An introduction to information graphics and visualization. New Riders: Berkeley, CA.

Cleveland, William S., and Robert McGill. (1984). Graphical perception: Theory, experimentation, and application to the development of graphical methods. Journal of the American Statistical Association 79(387): 531-554.

Cohen, Lawrence E. and Marcus Felson. (1979). Social change and crime rate trends: A routine activity approach. American Sociological Review 44(4): 588-608.

Feinberg, Richard A., and Howard Wainer. (2011). Extracting sunbeams from cucumbers. Journal of Computational and Graphical Statistics 20(4): 793-810.

Felson, Marcus, and Erika Poulsen. (2003). Simple indicators of crime by time of day. International Journal of Forecasting 19(4): 595:601.

Gigerenzer, Gerd. (2015). Calculated risks; How to know when numbers deceive you. Simon and Schuster: New York, NY.

Gigerenzer, Gerd, and Ulrich Hoffrage. (1995). How to improve Bayesian reasoning without instruction: Frequency formats. Psychological Review 102(4): 684-704.

Goel, S., Rao, J.M., Shroff, R. (2016). Precinct or prejudice? Understanding racial disparities in New York City's stop-and-frisk policy. The Annals of Applied Statistics, 10(1): 365-394.

Harcourt, Bernard E. (2008). Against prediction: Profiling, policing, and punishing in an actuarial age. University of Chicago Press: Chicago, IL. 
Hardt. M., Price, E., \& Srebro, N. (2016). Equality of opportunity in supervised learning. Advances in Neural Information Processing Systems, 29: 3315-3323.

Healy, Kieran, and James Moody. (2014). Data visualization in sociology. Annual Review of Sociology 40(1): 105-128.

Kastellec, Jonathan P., and Eduardo Leoni. (2007). Using graphs instead of tables in political science. Perspectives on Politics 5(4): 755-771.

MacDonald, John, Jeffrey Fagan, and Amanda Geller. (2016). The effects of local police surges on crime and arrests in New York City. PLOS ONE 11(6): e0157223.

MacEachren, Alan M. (2004). How maps work: Representation, visualization, and design. Paperback Edition. The Guilford Press: New York, NY.

Maltz, Michael D. (1996). From Poisson to present: Applying operations research to problems of crime and justice. Journal of Quantitative Criminology 12(1): 3-61.

Ratcliffe, Jerry H. (2002). Aoristic signatures and the spatio-temporal analysis of high volume crime patterns. Journal of Quantitative Criminology 18(1): 23-43.

Tufte, Edward R. (2001). The visual display of quantitative information. $2^{\text {nd }}$ Edition. Graphics Press: Chesire, CT.

Wain, Neil, and Barak Ariel. (2014). Tracking of police patrol. Policing 8(3): 274-383.

Wang, Ketong, Jenna K. Simandl, Michael D. Porter, Andrew J. Graettinger, and Randy K. Smith. (2016). How the choice of safety performance function affects the identification of important crash prediction variables. Accident Analysis and Prevention 88: 1-8.

Weisburd, David, Alese Wooditch, Sarit Weisburd, and Sue-Ming Yang. (2015). Do stop, question, and frisk practices deter crime? Evidence and microunits of space and time. Criminology \& Public Policy 15(1): 31-56.

Wheeler, Andrew P. (2015). What we can learn from small units of analysis. SSRN Working paper, https://papers.ssrn.com/sol3/papers.cfm?abstract_id=2626564.

Wheeler, Andrew P. (2016). Tables and graphs for monitoring temporal crime trends: Translating theory into practical crime analysis advice. International Journal of Police Science \& Management 18(3): 159-172.

Wheeler, Andrew P., and Tomislav Kovandzic. (2017). Monitoring volatile homicide trends across U.S. cities. Forthcoming in Homicide Studies.

Zeng, J., Ustun, B., \& Rudin, C. (2017). Interpretable classification models for recidivism prediction. Journal of the Royal Statistical Society Series A: Statistics in Society, 180(3): 689-722. 